\title{
Study on Entry Mechanism of Offshore Equipment Manufacturers under Technology Innovation
}

\author{
Xiaoyan Ge \\ School of Economics and Management, Harbin Engineering University \\ Nantong Street 154, 150001,Harbin, China \\ deepblue550302576@qq.com
}

\begin{abstract}
Concern about the poor performance of traditional shipbuilding industry, in China and elsewhere, is coming at a time when new-type offshore equipments are demanding more and becoming increasingly complex under technology innovation. the government encourages shipbuilding enterprises enter offshore equipment manufacturers, especially the emerging offshore oil \& gas equipment ones. The paper explores the problems and solutions in aligning between the government and enterprises during the entering process, following the basic principles of evolution game, and constructs the evolution game model of government-enterprise. It focuses on analyzing the factors of selecting strategies by various game bodies, then discusses the payment functions of main bodies under different strategies, finally establishes the corresponding replication dynamic equation to seek evolution stability strategies. The simulation on the dynamic evolution processes indicates the proposed algorithm is effective and feasible.
\end{abstract}

Keywords: offshore equipment manufacturers, technology innovation, entry mechanism, evolutionary game

\section{Introduction}

Offshore equipment is abbreviation for offshore engineering technology and equipment, it is a kind of large-scale engineering and auxiliary equipment, which is applied in marine resources (currently mainly include offshore oil and gas resources) exploration and development as well as transportation and some other aspects. The emerging offshore oil \& gas equipment manufacturing enterprises with high investment, risk and return characteristics are mainly engaged in constructing offshore equipment such as drilling platform, production platform, floating production oil storage vessel, crane ship, pipe laying vessel, trenching-pipe laying ship and diving operation vessel, which can be applied in offshore oil and gas exploration, storage and transportation, etc. In this study, we call this kind enterprise as Haizhuang for short. The most complicated and numerous technology is claimed in offshore equipment manufacturers, leading technology will directly determine the future development of equipment manufacturing enterprises. In order to enhance the competitiveness of offshore equipment manufactures and avoid fragmentation and duplication in technology innovation, the government assesses innovation capacity of now-existing shipbuilding enterprises, encourages those capable of technological innovation enter the offshore equipment manufactures. This study researches the behaviors between the government and enterprises under technology innovation, and analyzes the impact of the game action between them, finally puts forward some policy decisions for the government's reference. 


\section{Evolutionary Stable Strategy and Evolutionary Game Model}

Evolutionary game theory combines the game theory analysis with the dynamic analysis of the evolutionary process, no longer assumes people with full rational, but hold that, the game party achieves game equilibrium just by trial and error. This process is similar to biological evolution. Evolutionary stable strategy (ESS) is a strategy which, if adopted by a population in a given environment, cannot be invaded by any alternative strategy that is initially rare. It is relevant in game theory, behavioural ecology, and evolutionary psychology. An ESS is an equilibrium refinement of the Nash equilibrium. The function of the evolutionary process to achieve game equilibrium selection theory proposed by Maynard[1] and Price[2], the theory is used as an important analysis tool in theoretical study and application study. In recent years, studies continue to enrich, Bach, Helvike and Chistiansen[3]studied evolutionary game from divergent perspective, Hofbauera and Sandholmb[4]studied evolutionary game in the case of random disturbance.

The impact factors of Haizhuang manufacturing enterprises entry variable mainly as follows:

\subsection{Definition A}

Impact factors of Haizhuang manufacturing enterprises:

1) Profit $P e$,since offshore oil \& gas equipment manufacturing industry usually get larger profit margins than traditional shipbuilding industry, equipment manufacturing enterprises are ready to entry in no exceptional circumstances.

2) Entry costs $C e$, entry costs can lower profits, which also measures the business risk as main variable. Entering Haizhuang manufacturing enterprises must pay for the introduction of advanced technology and talent, new fixed assets expenses, depreciation of equipment in advance, staff training and other substantial costs are also needed, which are the main factors hindering enterprises to enter[5].

3) Loss of knowhow $L t$, the entry of Haizhuang manufacturing enterprises have adverse effects on knowhow capital of traditional shipbuilding enterprises, technical personnel, technical equipment and technical data will be lost undervalued because of enterprises restructuring[6].

4) Government encourage and funding $I g$, the government funds through institutional arrangements encourages Haizhuang manufacturing enterprises to entry actively and spontaneously[6].

5) Reward of technology innovation $R t$, reward is financial incentives for technology innovation after entry.

\subsection{Definition B}

Impact factors of the government:

1) Original tax $T_{0}$, during routine operations Haizhuang manufacturing enterprises must pay taxes, but when traditional Haizhuang manufacturers exit, the government's original tax becomes $0, T_{0}=P e * r, r$ is Haizhuang manufacturing enterprises integrated tax rate.

2) New tax $T_{1}$, traditional Haizhuang manufacturers transforms into oil and gas equipment manufacturing enterprises, in-situ planning and adjustment of regional economic development structure for investment, new oil and gas equipment manufacturing enterprises pay new taxes.

Assumptions: Haizhuang manufacturing enterprises exiting and entering new enterprises is carried out simultaneously[6], so $T_{1}=\Delta P e$. 
3) Treatment costs after entering $G m$,after traditional Haizhuang manufacturing enterprises exit, many old facilities need to be removed and reconstructed, which increases environmental control costs and social management costs for re-employment and placement of the dismiss.

4) Government incentive payments funded $G$, local government encourages local traditional Haizhuang manufacturing enterprises to enter oil and gas equipment manufacturing industry by accepting the central government transfer payments and fiscal spending.

Assumptions: local governments receiving transfer payments from the central government are incentives proportional with those which Haizhuang manufacturing enterprises obtained from the local government funding[7], so, $G_{1}=\alpha G c$, $0<\alpha \leq 1, G l$ is local governments encouraging funding, $G c$ is represents the central government transfer payments.

5) Reward of technology innovation $R t$, reward financial incentives for technology innovation after entry.

Assumptions: reward of technology innovation and profits of Haizhuang manufacturing enterprises are proportional. $R t=\beta P e, 0<\beta \leq 1$.

6) Derivative costs $C i$, administrative consumption of local governments. Such as cost by checking and coordination of resources before the exercise of administrative measures.

7) Time value $V$, the time value losses caused by Haizhuang manufacturing enterprises entry delay[8].

Assumptions: government funding through incentive measures will make Haizhuang manufacturing enterprises enter more quickly.

\subsection{Definition C}

$P_{1}$ is probability of manufacturing enterprises entry, $P_{2}$ is the incentives for local governments to subsidize efforts to implement, then manufacturing enterprises $M$ and Government $G$ act under different strategies, game matrix is shown as follow Figure 1.

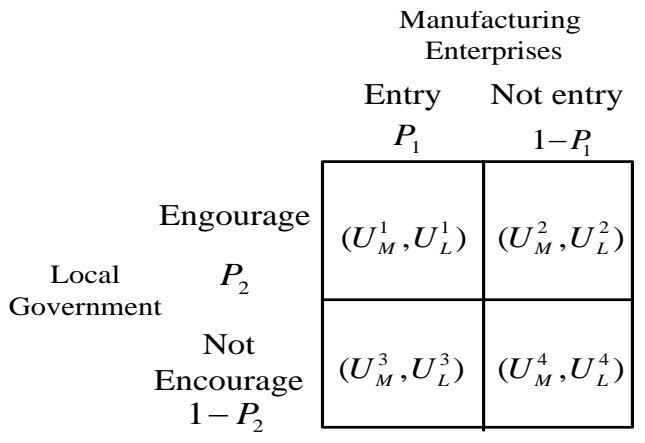

Figure 1. Game Matrix

Payment functions between enterprises and local governments as follows:

$$
\begin{aligned}
& U_{G}^{1}=G c-\alpha G c+\Delta P e-C i+V \\
& U_{M}^{1}=-C e-L t+\alpha G c \\
& U_{G}^{2}=P e(\gamma+\beta)-C m-C i \\
& U_{M}^{2}=P e(1-\gamma-\beta)
\end{aligned}
$$




$$
\begin{aligned}
& U_{G}^{3}=G c+\Delta P e \\
& U_{M}^{3}=-C e-L t \\
& U_{G}^{4}=P e(\gamma+\beta)-C m \\
& U_{M}^{4}=P e(1-\gamma-\beta)
\end{aligned}
$$

\section{Solution of ESS Enterprise Entry}

We obtained expected revenue functions of both players based on payment functions between the government and Haizhuang manufacturing enterprises as follows:

\subsection{Manufacturing Enterprises Expected Revenue Function $E_{M}$}

$$
\begin{aligned}
& E_{\text {entry }}=P_{2}(-C e-L t+\alpha G c)+\left(1-P_{2}\right)(-C e-L t)=\alpha P_{2} G c-C e-L t \\
& E_{\text {notentry }}=P_{2}[P e(1-\gamma-\beta)]+\left(1-P_{2}\right)[P e(1-\gamma-\beta)]=P e(1-\gamma-\beta) \\
& E_{M}=P_{1} E_{\text {entry }}+\left(1-P_{1}\right) E_{\text {notentry }}
\end{aligned}
$$

\subsection{Local Government Expected Revenue Function $E_{G}$}

$$
\begin{aligned}
& E_{\text {encourage }}=P_{1}(G c-\alpha G c+\Delta P e-C i+V)+\left(1-P_{1}\right)[(P e(\gamma+\beta)-C m-C i] \\
& E_{\text {notencourage }}=P_{1}(G c+\Delta P e)+\left(1-P_{1}\right)[(P e(\gamma+\beta)-C m] \\
& E_{G}=P_{2} E_{\text {encourage }}+\left(1-P_{2}\right) E_{\text {notencourage }}
\end{aligned}
$$

\section{Solution of ESS Replication Dynamic Equation}

\subsection{Replication Dynamic Equation of Manufacturing Enterprises}

$$
\begin{aligned}
& F\left(P_{1}\right)=\frac{d P_{1}}{d t}=P_{1}\left(E_{\text {entry }}-E_{M}\right)=P_{1}\left(1-P_{1}\right)\left[\left(\alpha P_{2} G c-C e-I t\right)-P e(1-r-\beta)\right] \\
& F\left(P_{1}\right)=P_{1}\left(1-2 P_{1}\right)\left[\left(\alpha P_{2} G c-C e-L t\right)-P e(1-r-\beta)\right] \\
& \quad F\left(P_{1}\right)=\frac{d P_{1}}{d t}=0, \text { solution: } P_{1}^{*}=0, P_{1}^{*}=1, \\
& \text { Set } \quad P e(1-r-\beta)+L t+C e \\
& P_{2}^{*}=\frac{P G c}{\alpha G(1-r)}
\end{aligned}
$$

According to the theorems and nature of RD and ESS: when $F\left(P_{1}\right)=0, F^{\prime}\left(P_{1}\right)<0$, $P_{1}^{*}$ is evolutionary stable strategy.

1) When $P_{2}=\frac{P e(1-r-\beta)+L t+C e}{\alpha G c}, F\left(P_{1}\right)=0, \quad F^{\prime}\left(P_{1}\right)=0$, namely all the axes levels are in the steady states, when the encouragement efforts of the government reach $P_{2}^{*}=\frac{P e(1-r-\beta)+L t+C e}{\alpha G c}$, the entry possibility of manufacturing enterprises is stable. 


$$
P_{2}>\frac{P e(1-r-\beta)+L t+C e}{\alpha G c}, P_{1}^{*}=0, P_{1}^{*}=1, \text { then } F^{\prime}(0)>0,
$$

$F^{\prime}(1)<0$. At this time, the globally unique evolution stability strategy is $P_{1}^{*}=1$, when the encouragement efforts of the government reach certain level , and show gradual increasing trends, the entry possibility of manufacturing enterprises increases gradually, finally entry is the optimal choice.

$$
\text { 3) When } P_{2}<\frac{P e(1-r-\beta)+L t+C e}{\alpha G e}, P_{1}^{*}=0, P_{1}^{*}=1 \text {, then } F^{\prime}(0)<0 \text {, }
$$

$F^{\prime}(1)>0$.At this time, the globally unique evolutionary stable strategy is $P_{1}^{*}=0$, when the encouragement efforts of the government fail to reach certain level, and show gradual decreasing trends, the entry possibility of manufacturing enterprises reduces gradually, finally entry is not the optimal choice. Figure 2 shows the dynamic trends and stability of manufacturing enterprises.
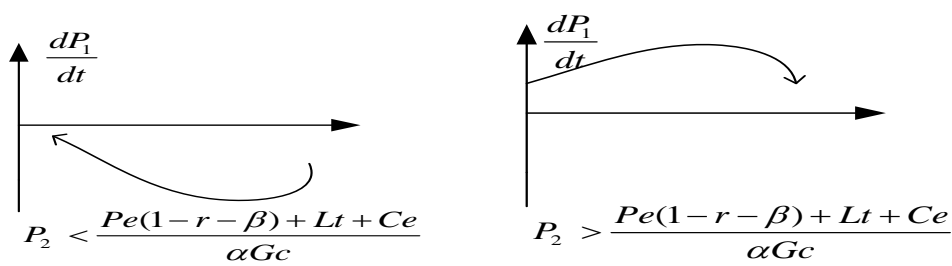

\section{Figure 2. Phase Figures of Replication Dynamic Trends of Manufacturing Enterprises}

\subsection{The Replication Dynamism Equation of the Government}

$$
\begin{aligned}
& \quad F\left(P_{2}\right)=\frac{d P_{2}}{d t}=P_{2}\left(E_{\text {encourage }}-E_{G}\right)=P_{2}\left(1-P_{2}\right)\left[(V-\alpha G c) P_{1}-G\right] \\
& \quad F\left(P_{2}\right)=P_{2}\left(1-2 P_{2}\right)\left[(V-\alpha G c) P_{1}-G\right] \\
& \quad F\left(P_{2}\right)=\frac{d P_{2}}{d t}=0, \text { solution: } P_{2}^{*}=0, P_{2}^{*}=1, P_{1}^{*}=\frac{C i}{V-\alpha G c}
\end{aligned}
$$

According to the theorems and nature of RD and ESS: When $F\left(P_{2}\right)=0, F^{\prime}\left(P_{2}\right)<0$ $P_{2}^{*}$ is evolution stability strategy.

1) When $P_{1}=\frac{C i}{V-\alpha G c}, F\left(P_{2}\right)=0, F^{\prime}\left(P_{2}\right)=0$, namely all the axes levels are in the steady states, when the entry possibility of manufacturing enterprises reaches $P_{1}^{*}=\frac{C i}{V-\alpha G c}$, the encouragement efforts of the government are stable.

2) When $P_{1}>\frac{C i}{V-\alpha G c}, P_{2}^{*}=0, P_{2}^{*}=1$, then $F^{\prime}(0)>0, F^{\prime}(1)<0$.At this time, the globally unique evolutionary stable strategy is $P_{2}^{*}=1$, when the entry possibility of manufacturing enterprises reaches certain level, show a gradual increasing trend, the encouragement efforts granted by the government increase gradually, finally increasing encouragement efforts is optimal choice. 
3) When $P_{1}<\frac{C i}{V-\alpha G c}, P_{2}^{*}=0, P_{2}^{*}=1$, then $F^{\prime}(0)<0, \quad F^{\prime}(1)>0$. At this time, the globally unique evolutionary stable strategy is $P_{2}^{*}=0$, when the entry possibility of manufacturing enterprises is small enough, show a gradual decreasing trend, the encouragement efforts granted by the government decrease gradually, finally decreasing encouragement efforts is optimal choice. Figure 3 shows the dynamic trends and stability of encouragement efforts of the government.
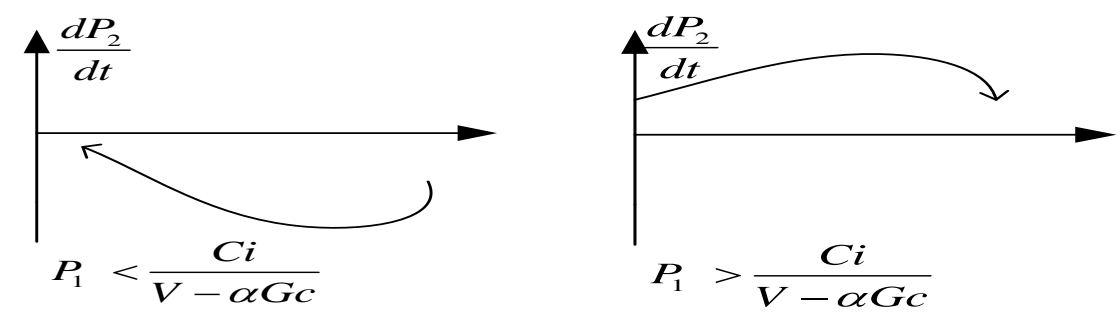

Figure 3. Phase Figures of Replication Dynamic Trends of the Government

\section{Group Replication Dynamism and Stability}

Based on the above analysis, Figure 4 shows the game replication dynamism relationships between the government and manufacturing enterprises. In Figure 4, point $O$ and $\mathrm{B}$ are in the ESS states, point $\mathrm{O}$ represents the state that government does not take any encouragement incentives, manufacturing enterprises do not enter. Point B represents that the government takes the greatest encouragement efforts under the fiscal budget constraint, manufacturing enterprises actively enter. In the upper right area of Figure 4, the game behaviors between government and manufacturing enterprises converge to point $\mathrm{B}$, the system is in Pareto optimal equilibrium B $(1,1)$. In the lower left area, the game behaviors between the government and manufacturing enterprises converge to point $\mathrm{O}$, the system is Pareto inferior equilibrium $\mathrm{O}(0,0)[9]$. Except the two points in the area, the converging directions of game behaviors between the government and manufacturing enterprises are uncertain.

If game players converge to Pareto optimal equilibrium with the greatest possibility, namely $\mathrm{B}(1,1)$ point, the game strategies between manufacturing enterprises and the government lie in the upper right area of $D\left(P_{1}^{*}, P_{2}^{*}\right)$. At this time

$$
P_{1}>\frac{C i}{V-\alpha G c}, \quad P_{2}>\frac{P e(1-r-\beta)+L t+C e}{\alpha G c} \text {.When }_{2}^{*}=\frac{P e(1-r-\beta)+L t+C e}{\alpha G c},
$$

the profits of Haizhuang manufacturing enterprises $P e$, loss of knowhow $L t$, entry cost $\mathrm{Ce}$ have positive correlation relationships with $P_{2}^{*}$. integrated tax rate of Haizhuang manufacturing enterprises $r$, the encouragement subsidy of local government $\alpha G c$, reward of technology innovation rate $\beta$ have negative correlation relationships with $P_{2}^{*}$. The government can increase integrated tax rate of traditional enterprises, increase reward of technology innovation, weaken values of loss of knowhow to reach $P_{2}>P_{2}^{*}$. According to replication dynamism equation of manufacturing enterprises, entry is the optimal choice. 


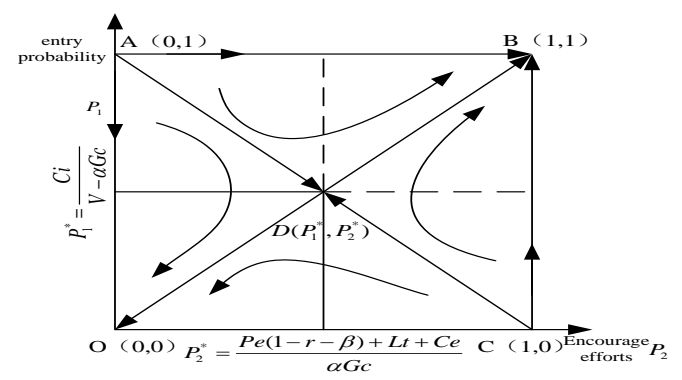

\section{Figure 4. Replication Dynamic Relationships of Game Group}

When $P_{1}^{*}=\frac{C i}{V-\alpha G c}$, derivative cost $C i$, the encouragement subsidy from local government $\alpha G c$ have positive correlation relationships with $P_{1}^{*}$, time values $V$ has negative correlation relationships with $P_{1}^{*}$. The government can increase the encouragement subsidy of local government and spending on administrative checking and coordination to reach $P_{2}>P_{2}^{*}$. According to the replication dynamic equation of local government, increasing encouragement efforts is the optimal choice[10].

In summary, we can summarize the game action strategy choices between the government and Haizhuang manufacturing enterprises, when the possibilities of both behaviours lie in the upper right area of Figure 4, the game behaviors between the government and Haizhuang manufacturing enterprises converge to Pareto optimal equilibrium automatically.

\section{Numerical Demonstration}

Based on the model above, we use Matlab to simulate the dynamic evolution processes of game strategies between the government and offshore engineering equipment manufacturers under different initial states[11].

Assume that the parameters of payment functions in the game matrix between Haizhuang manufacturing enterprises and the government are as follows (Unit: 100 million RMB): profit $P e=5$, entry cost $C e=5$, loss of knowhow $L t=0.5$, the central transfer payments $G c=20$, local transfer reward coefficient $\alpha=80 \%$, reward of technology innovation $R t=\beta P e=10 \% * 5=0.5$, original tax $T_{0}=P e * r=5 * 30 \%=1.5$. The dynamic evolution processes of game action strategies of offshore equipment manufacturers are shown as follows: if $P_{2}<0.5$, this study sets $P_{2}=0.3$, the dynamic evolution processes of game action strategies of Haizhuang manufacturing enterprises are shown in Figure 5. According to graphical analysis, finally the game action strategies of entry choice of Haizhuang manufacturing enterprises all converge to 0 under the initial possibilities of various game entry strategies, namely when the government chooses the lower encouragement efforts in the game process, Haizhuang manufacturing enterprises will choose exit game action strategy. If $P_{2}>0.5$, this study sets $P_{2}=0.8$, the dynamic evolution processes of game action strategies of Haizhuang manufacturing enterprises are shown in Figure 5. According to graphical analysis, finally the game action strategies of entry choice of Haizhuang manufacturing enterprises all converge to 1 under the initial possibilities of various game entry strategies, namely when the government chooses the greater encouragement efforts in the game process, Haizhuang manufacturing enterprises will choose entry game action strategy. 

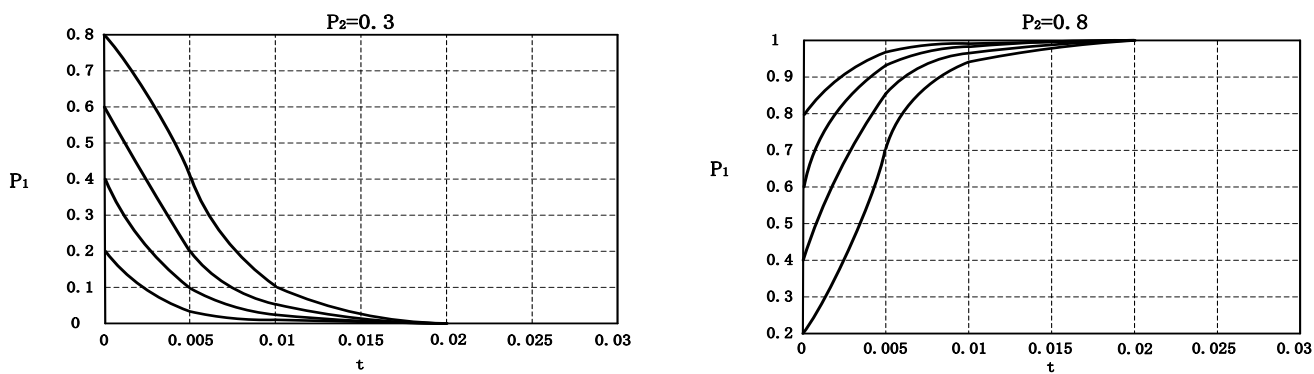

\section{Figure 5. ESS Processes of Game Action Strategies of Haizhuang Manufacturing Enterprises}

\section{Discussion and Conclusion}

This paper has argued that decisions of traditional ship-building enterprises enter offshore oil \& gas equipment manufacturing industry are influenced by the government behavior. A notable feature of the China ship-building enterprises in the recent 10 years have been declining on orders and profits. offshore oil \& gas equipment manufacturing industry, which hold high value, high technique and high risk are a appropriate trend to transform. In offshore oil \& gas equipment manufacturing industries, technology innovation has largely become the most basic premise for keeping the enterprise competitiveness. This assumes particular importance when enterprise transformation is viewed from a technology innovation promotion perspective.

By empirically establishing the evolutionary game model of evolutionary stable strategy of enterprise entry and replication dynamic equation between government and enterprise, we seek to focus the attention on government administrative behaviors can affect the decision of enterprise and we get the optimal choice of enterprise under different motivation from government. Based on the model, we use Matlab to simulate the dynamic evolution processes of game strategies between the government and offshore engineering equipment manufacturers under different initial states, the practical implication of the results is that Haizhuang manufacturing enterprises' entering game action strategy requires a greater encouragement efforts from government in the game process.

In conclusion, this study offers new insights that Haizhuang manufacturing enterprises will choose entry game action strategy when government chooses the greater encouragement efforts in the game process. The entry institutions of enterprises break the lifelong institutions of industry, encourage traditional enterprises transform into the offshore oil \& gas equipment manufacturing enterprises, which will be conductive to enhance competitive strength and production efficiency. The game action decisions of the entry of offshore equipment manufacturers have positive correlation relationships with the encouragement efforts granted by the government, at the same time, the game action strategies of offshore equipment manufacturers will have influences on the game action strategies of the government. Assume that the government chooses reasonable entry mechanism according to the offshore equipment manufacturing industry planning and policy of the nation, achieving Pareto optimal equilibrium of game participants is feasible.

\section{References}

[1] S. J. Maynard, "The Theory of Games and the Evolution of Animal Conflict", Journal of Theory Biology , no. 47, (1973), pp.209-221.

[2] S. J. Maynard and G. R. Price, "The Logic of Animal Conflicts", Nature, no. 246, (1974), pp.15-18.

[3] L. A. Bach, T. Helvikc and F. B. Christiansen, "The Evolution of N-player Cooperation-threshold Games and ESS Bifurcations", Journal of Theoretical Biology, no. 238, (2006), pp. 426-434. 
[4] J. Hofbauera and W. H. Sandholmb, "Evolution in Games with Randomly Disturbed Payoffs", Journal of Economic Theory, no. 132, pp.47-69, (2007).

[5] P. K Levine and W. Pesendorfer, "The Evolution of Cooperation through Imitation", Games and Economic Behaviors, no. 58, pp.293-315, (2007).

[6] B.-H. Guo, Z.-G. Liu and Q. Fang, "Study of Regional Energy-Intensive Industry's Exit Mechanism Based on Evolutionary Game", Chinese Journal of Management Science, pp.79-85, (2012).

[7] Z. Wang and X. Xu, "Analysis on Evolutionary Game of "Government-Industry-University-Institute", Cooperative Innovation. Science \& Technology and Economy, (2013), pp.37-43.

[8] J.-F. Liu and C. W. Xu, "Evolutionary Game Analysis of Supply Chain Integration and Innovation", Systems Engineering, (2011), pp.8-13.

[9] J. Tang and H. Yang, "Research on Development Mechanism and Path of Enterprise Competitiveness from the Perspective of Evolutionary Game", Yunnan Finance \& Economics University Journal of Economics \& Management, (2012), pp.108-114.

[10] L. Xu, "The Discussion about the Best Choice of Countermeasure to Improve the Independent Innovation Ability of Chinese Equipment Manufacturing Industry", Soft science, (2010), pp. 33-38.

[11] J. Barlow, "Innovation and learning in complex offshore construction projects", Research Policy, no. 29, (2000), pp.973-989. 
International Journal of Control and Automation

Vol. 9, No. 11 (2016) 